\title{
Derechos humanos y la ética de la banda de ladrones. Aproximaciones filosóficas a los supuestos éticos en que se soporta el discurso de los derechos humanos en la actualidad 1
}

(Recibido: Junio 5 de 2012 Aprobado: Julio 4 de 2012)

Israel Arturo Orrego Echeverría ${ }^{2}$

\section{Resumen}

El presente texto aborda desde una perspectiva crítica y filosófica el problema de los Derechos Humanos en el contexto de la reflexión latinoamericana. Para ello, se identifica que cualquier enunciación de dichos discursos, está atravesada por una larga tradición latinoamericana entorno a la pregunta por la condición de humanidad y/o los constructos ideológicos que entorno al problema se han dado en el pensar latinoamericano, incluso desde los tiempos de la colonización española. Así, por ejemplo, se evidencia la forma como desde la denominada "escolástica latinoamericana", la reflexión filosófica ha girado principalmente en torno al tema de la humanidad, elementos que entre otras signan la posibilidad de enunciación de los derechos humanos en el ámbito académico latinoamericano.

Lo anterior obliga a que el discurso de los derechos humanos sea asumido, en el ámbito de la presente reflexión, desde una perspectiva crítica de los mismos, permitiendo poner de manifiesto los elementos éticos bajo los cuales dichos discursos se han enunciado, pues bajo éstos en la actualidad se han legitimado toda una serie de violación "legítima" de los mismos, lo que Franz Hinkelammert ha denominado la "ética de la banda de ladrones".

\section{Palabras Clave}

Derechos Humanos, Ética de la Banda de Ladrones, escolástica latinoamericana, humanismo, utopía.

\section{Human rights and the ethics of the band of thieves. Philosophical approaches to the ethical suppositions that support the discourse of human rights today}

\section{Abstract}

This article approaches the problem of Human Rights in the context of Latin American reflection from a critical and philosophical perspective. In order to do this, the author demonstrates that any enunciation in Human Rights discourse is traversed by a long Latin American tradition which considers the human condition and/or the ideological constructions which said discourse has troubled since Spanish colonization. Therefore, it is shown how philosophical reflection from so-called "Latin American scholasticism", has generally revolved around themes of humanity, elements that, among other things, signify the possibility of enunciation of Human Rights in the Latin American academy.

This has obliged Human Rights discourse to be subsumed, in the realm of present reflection, into a critical perspective of the same, permitting a manifestation of the ethical elements under which said discourses have been enunciated. This article outlines the ways in which, in actuality, under this rubric, all manner of "legitimate" violence has been carried out through the very elements of the discourse. This is what Franz Hinkelammert has determined as the "Ethic of the Band of Thieves."

\section{Kev Words}

Human Rights, Ethic of the Band of Thieves, Latin American scholasticism, humanism, utopia.

1 Artículo de reflexión que desde una perspectiva interpretativa y crítica, indaga por los fundamentos éticos y humanistas del discurso de los derechos humanos en América Latina.

2 Profesional en filosofía, Licenciado en Ciencias Teológicas, Bachiller superior en teología, Esp. Educación y política. Maestría en Filosofía Latinoamericana. Docente-investigador CED / UNIMINUTO, Docente Teología Seminario Menonita de Colombia. arturo.orrego@gmail.com 


\section{Antecedentes de la reflexión humanista y de derechos en América Latina}

Resulta paradójico y no poco problemático pretender hablar de los derechos humanos en contextos particularmente afectados por la violación de los mismos. Por otra parte $-y$ como si lo anterior fuese poco- el ya maltrecho camino de reflexión en torno a los derechos humanos -particularmente después de 1948 con la Asamblea de las Naciones Unidas- da la apariencia de que cualquier aproximación a la temática, tienda al ya desgastado, pero tan en boga, discurso de los derechos, sobre el que se tejen y sostienen toda una serie de racionalidades, apetencias políticas, lógicas de poder, pero principalmente presupuestos éticos y antropológicos. De fondo, parece estar entonces en el discurso de los derechos la aún irresuelta pregunta por lo humano, cuya solución tienden las propuestas éticas a dar respuesta desde diferentes flancos.

Lo humano entonces, es un punto clave de reflexión en torno a los derechos humanos, no por la simple enunciación del término en la frase "derechos humanos", sino por el hecho de que la condición antropológica de los sujetos humanos, siempre ha sido cuestión de discusión en el entramado histórico. Así lo atestiguan las ya conocidas discusiones en torno a la humanidad de los indios de las américas en el siglo XVI y los derechos connaturales a su condición, en otras palabras las formas de relacionamientos de los sujetos, dependen en gran medida de la condición de humanidad que se haya adjudicado al otro. Así, no sólo se entreteje el discurso de los derechos humanos con la antropología, sino que se corresponde también una determinada ética en que acompaña y soporta dicha comprensión de lo "humano". Se hacen entonces inseparables en una perspectiva de análisis latinoamericana -como lugar de enunciación del discurso-, la reflexión ética y antropológica crítica de los derechos humanos.

$Y$ es que precisamente el elemento de la constitución de lo humano, y los derechos que le son naturales por dicha condición, ha sido una de los temas que ha signado la reflexión en América Latina. Baste recordar el fértil terreno abonado por la "escolástica latinoamericana" en pleno despliegue del proceso de colonización de América, y apenas en desarrollo de las ideas humanistas de Erasmo en el Viejo Mundo; hecho que hace de los discursos de la escolástica latinoamericana un verdadero ejemplo de resignificación de la condición humana. Al respecto Guadarrama (2002) recuerda que "La conquista de América puso a prueba, como en otras ocasiones de expansiones coloniales, el tema de cuál es el elemento dominante en las acciones humanas» (Guadarrama, 2020,134).

Es evidente entonces que una de las principales preocupaciones del pensamiento latinoamericano ha estado ligada al tema de la humanidad y los derechos que son propios a dicha humanidad. Es decir, si bien, el discurso actual de los Derechos Humanos es heredero de la producción humanista de occidente -de corte sajón-, particularmente después de la revolución francesa y americana de finales del siglo XVIII y con una marcada tendencia después de las declaraciones de los derechos del hombre y posteriormente de los Derechos Humanos en el siglo XX, la producción latinoamericana de tiente hispánico, con mucha anterioridad ya había abordado de manera seria la cuestión de la humanidad.

El humanismo ha sido, es y será consustancial a la reflexión filosófica en América Latina. Está presente desde los primeros años de la conquista, cuando se produce la discusión sobre la justificación o no de tal empresa y situación de los aborígenes en la misma (Guadarrama, 140). 
Esta discusión por lo humano en América Latina, por criticada que pueda ser, pues paradójicamente se desarrolla principalmente en los círculos católicos, evidencia desde muy temprano el horizonte de lo que podría constituir el centro de la reflexión americana y el aporte para lo que hoy se establece como discurso hegemónico de los derechos humanos.

Ahora bien, la vinculación con lo humano en la reflexión americana, cuyos orígenes se remontan a 1511 con el fraile Anton de Montesinos cuando vincula el tema de la humanidad de los indios con la ética del conquistador -vínculos no dados en la reflexión ética ni humanista de la época- al cuestionar el "derecho" de los españoles para subyugar a los aborígenes, pregunta Montesinos «¿Con qué derecho y con qué justicia tenéis en tan cruel y horrible servidumbre aquestos indios? ¿Con qué autoridad habéis hecho tan detestables guerras a estas gentes que estaban en sus tierras mansas y pacíficas [...]" (Montesinos, 141), continuador de semejante gesta de los derechos humanos, será también el padre Bartolomé de las Casas, quien a mediados del siglo XVI y en pleno auge del Renacimiento humanista de Erasmo de Rotterdam en Europa, profundizará sagazmente el tema de los derechos de los indios. Interesantemente en la misma línea pero con gran amplitud, uno de los defensores de la humanidad de los indios, aunque no conoció sus tierras, fue Francisco de Vitoria, quien anticipándose varios siglos a la discusión "cultural" y su relación con los derechos de las gentes "[...] consideraba que no había ningún derecho para imponer una cultura sobre otra, una religión sobre otra, o normas institucionales" (143).

Por otra parte, la transversalidad de lo humano en el pensamiento americano, no se da sólo en el campo religioso y en la época de la colonia española y por españoles. Se da como una experiencia de vida en la periferia de la humanidad americana, lo que hace del discurso de los derechos y de la humanidad en el hemisferio, un asunto ético-político y no un simple enunciado humanista carente de valor práxiológico y fundado en la experiencia histórica de unos cuantos "Burgueses europeos". En otras palabras, si bien es cierto el discurso humanista surge en el paradójico seno de los pensadores hispánicos, esto se da únicamente gracias al encuentro particular con el ser indígena, con aquel Otro que fundará toda la ética levinasiana, pero será profundizada y concretizado en el Otro empobrecido del Ética de la Liberación de Enrique Dussel.

Así, los vínculos entre lo humano, lo ético y lo político, no son posibles de escindir de la reflexión y praxis americanas. Se postula entonces desde américa y ello desde sus orígenes y desencuentros con España, una determinada manera de comprender los derechos humanos que bien pude servirnos de análisis para la problemática actual de los derechos. Tanto es el vínculo primigenio de lo humano con lo ético, por lo menos desde la perspectiva Latinoamericana, que éste se evidencia aún en las reflexiones pedagógicas, a saber, particularmente la Pedagogía del Oprimido de Paulo Freire, quien establece como horizonte de la pedagogía, la dignificación de lo humano, es decir, establece un claro vínculo entre los humano, lo ético y lo pedagógico en América Latina.

El tema de la "Humanización" es fundamental en la obra del educador $y$, servirá en su reflexión como el puente para visibilizar la existencia concreta, es decir, de los cuerpos-oprimidos cuerposliberados (Machuca, 2011, 7). Freire, como educador humanista enfoca su trabajo en la construcción de un mundo más humanizado y la lucha contra todo aquello que deshumaniza en relación a la vida concreta. 
Son entonces, las "situaciones límites" aquellas condiciones que limitan la vocación del ser humano para "ser más" ${ }^{3}$, para ser sujeto activo en la transformación de las condiciones injustas y las concreciones impuestas por opresión. Al respecto, el pedagogo menciona que "La deshumanización es la condición a la que están sometidas las mayorías empobrecidas a quienes se les niega una vida digna: alimento, vivienda, salud, educación» (Freire 1993, 41), en relación a esa existencia concreta que se da para el "ser más", en otras palabras que humaniza a las mayorías:

Es importante insistir en que, al hablar del "ser más" o de la humanización como vocación ontológica del ser humano, no estoy cayendo en ninguna posición fundamentalista, por lo demás siempre conservadora. De ahí que insista también en que ésta "vocación", en lugar de ser algo a priori de la historia, es por el contrario algo que viene constituyéndose en la historia...

El sueño de la humanización, cuya concreción es siempre proceso, siempre devenir, pasa por la ruptura de las amarras reales, concretas, de orden económico, político, social, ideológico, etc., que nos están condenando a la deshumanización (Freire 1993, 95).

Por tanto, la tarea educativa desde esta perspectiva será la de potencializar la vocación de los seres humanos para aquel "ser más"; para superar todo aquello que no deja vivir plenamente y que por ende no permite un mundo humanizado "La vocación para la humanización, según la pedagogía freireana, es la marca da la naturaleza humana que se expresa en la propia búsqueda de ser más..." (Machuca, 2011, 9).

3 En la Pedagogía del Oprimido, el "ser más" está relacionado con el desafío de libertad para los oprimidos, como la búsqueda de la humanización; Es a partir del dialogo crítico y problematizador que será posible que los oprimidos construyan caminos para "ser más".
Se hace evidente entonces, la manera como el tema de los derechos humanos ha estado atravesado en la reflexión y praxis latinoamericana, generando no sólo aportes en el marco de los Derechos Humanos, sino haciendo de éstos un elemento articulador de la experiencia intelectual y humana en América Latina, pero siempre desde una perspectiva crítica.

\section{Actualización de los Derechos Humanos al mundo globalizado y transnacionalizado}

El análisis de los fenómenos sociales y particularmente del actual sistema económico trasnacional en el que se configuran las estructuras mínimas en que se tejen las dinámicas culturales y de la subjetividad misma "del sujeto", de tal suerte que se establecen dinámicas de relacionamiento que necesariamente deben estar legitimadas no sólo en una estructura económica -en el particular transnacionalizada- sino en una serie de comportamientos que tienden a ser idealizados y consiguientemente legitimados. Es decir, se establece una determinada ética que configura la legitimidad de determinadas acciones y constituye el marco de lo que puede considerarse, Derechos Humanos en la actualidad. Para ello, es menester evidenciar, a manera muy somera, las dinámicas del actual sistema de relacionamiento económico, político y cultural, en el cual se enmarca la perspectiva de los derechos humanos en el mundo globalizado.

William Robinson (2007) recuerda que el proceso del capitalismo global ha tenido unas transformaciones que bien deben ser analizadas en detalle y que escapan a la estructura de análisis de la teoría sistema-mundo, que hasta hace apenas unas décadas, era la que mejor podría explicar el funcionamiento del capitalismo mundial. Robinson, hace un detallado análisis de las cuatro etapas de la lógica de acumulación capitalista, evidenciando 
particularmente el funcionamiento de la última de éstas, que desde su perspectiva es la etapa transnacionalizada (Robinson, 20). Al respecto recuerda Robinson que:

Hoy día estamos en las primeras fases de la cuarta época del capitalismo (globalización), destacada tecnológicamente por el microchip y el computador-símbolos de la "edad de la información"- y políticamente por el colapso de los intentos del siglo XX por el socialismo, y el fracaso de toda la generación de los movimientos nacionales de liberación del Tercer Mundo para ofrecer una opción frente al capitalismo mundial. (Robinson, 2007, 21).

Puede evidenciarse la manera como ésta etapa del capitalismo no sólo surge, sino que se presenta como la superación de los "movimientos nacionales de liberación", de los que hemos enunciado algunos antecedentes. Es decir, esta nueva etapa pretende presentarse como la "superación" del llamado a una ética de derechos, plasmados en el ideal socialista por parte de los mal llamados países tercer mundistas. Como si se tratara entonces de un paso más avanzado en el proceso de socialización política y económica mundial; lo que en realidad oculta la empresa racionalizadora-con su lógica funcional y utilitarista- y anti utópica de esta nueva etapa del capitalismo. Al respecto opina Hinkelammert que:

La secuencia anti-utópica bajo la cual el conservador [neoliberal] interpreta a los movimientos populares de protesta social, no es más que una creación fantasmagórica-una proyección-a la sombra del cual él prepara su propia aceleración de su lucha de clases desde arriba y los pasos consiguientes al terror conservador y a la trasformación de sus sociedad, cada vez más cerradamente interpretada como fortaleza. Dice Popper: "Las instituciones son como fortalezas. Tienen que estar bien construidas y además propiamente guarnecidas de gente (Hinkelammert, 2000, 110).

Así, tras la lógica "conservador" antiutópica del neoliberalismo actual, Hinkelammert recuerda una frase de Popper, que bien puede ejemplificar la profundización anti-utópica de la lucha de clases promovida desde "arriba" "quien busca el cielo en la tierra, construye el infierno"; tras esto se oculta acaso toda la empresa teológica y teleológica de la racionalidad capitalista, poniendo de manifiesto que la utopía en la actualidad es puesta por el capitalismo en manos de la tecnología, que no evidencia que Popper «[...] no supera la utopía ni logra una crítica de ella. Lo que hace es transformar de una utopía de liberación -de una utopía de la praxis- en una utopía del progreso técnico» (Hinkelammert ,187).

Según Robinson, esta nueva época del capitalismo transnacional está acompañada de la conformación y reconfiguración de unas clases con intereses transnacionales, pero que en el fondo conservan el mismo espíritu acumulativo capitalista de antaño, de allí que el análisis de Hinkelammert del anti-utopismo siga siendo relevante: «El proceso por el cual la gente es separada de los medios de producción, tal como a través de la conquista colonial o la pérdida de tierras a favor de los acreedores, se conoce como acumulación primitiva..." (Robinson, 2007, 22).

La estrategia ha cambiado. Quizá ya no devenga de la misma manera que en 1492 con la llegada de los españoles, sin embargo, la lógica del pillaje y el robo siguen siendo los imperativos del actual sistema. Por el contrario de lo esperado, -por Hayek, Adam Smit y Popper-el sistema de capitalismo global, es la forma más efectiva de la concentración de los flujos de capitales mundiales, de tal forma que los países empobrecidos, se ven forzados a entrar en la lógica transnacional. 
El capitalismo para funcionar, debe "modificar las relaciones sociales" (/bíd.), de forma tal que se dé una "ampliación extensiva", en otras palabras, el capitalismo per se es extensivo, tanto como acumulativo; y para conseguir este fin es menester transformar las relaciones sociales y con ello los criterios de lo humano y los derechos que le protegen, de tal manera que se configure la sociedad y las fuerzas de producción en beneficio de las élites trasnacionales.

Sin embargo, cabe preguntarse a la luz de las diferencias epocales del capitalismo, a más de las relaciones propiamente productivas, económicas, políticas, culturales y demás que puedan tejerse para la configuración y sostenimiento -con sus respectivas épocas- del sistema de acumulación, por la forma como este sistema legitima sus acciones, pues para actuar como un sistema, necesariamente requiere de la cooperación de los diferentes estamentos de la sociedad. En otras palabras es necesario plantear preguntas de fondo-es decir, de carácter filosófico- al sistema mismo de acumulación y las estructuras simbólicas y éticas que permiten su vigencia.

Al respecto, Franz Hinkelammert (2002), en la propuesta de su teoría del sujeto, considera importante develar la ética propia del actual sistema globalizado, pues, desde su perspectiva, hay una lógica que a traviesa la esencia misma, más allá de sus épocas y etapas del capitalismo, es, en palabras del alemán, la ética de la Banda de Ladrones.

Es necesario al respecto recordar que una de las premisas de las ciencias positivas, quizá desde el mismo David Hume, es la de separar la ciencia de la ética, de la misma forma que Adam Smith pretendió separar la economía de la ética y que el actual sistema capitalista separa sus intervenciones económicas de la ética. Hinkelammert opina que esta forma de comprender la ética, trata la misma como juicio de valor y no propiamente como dimensión de toda la acción humana (Hinkelammert ,199), es decir, en un sentido de totalidad de la acción.

La forma como este modelo ético legitima su racionalidad es generando por la acción fragmentada, y ello por la mediación de la relación medio-fin. En otras palabras se establece una ética del mercado, con su propia racionalidad y formas de legitimarse, sin ésta, el capitalismo globalizado, tal como lo conocemos, no sería posible.

Ahora bien, esta ética, por ser la ética del mercado transnacional, necesita del establecimiento de normas que rijan a nivel internacional y éstas normas no pueden ser únicamente normas o leyes económicas, sino que se requieren de normas éticas transnacionales.

Al respecto Hinkelammert recuerda la «visible afinidad de las declaraciones de los derechos humanos del siglo XVIII y las normas de la ética del mercado» (Hinkelammert, 200). Si bien es cierto, dicha declaración no se reduce a la ética del mercado, ciertamente contiene las normas básicas de la ética del mercado, como son el reconocimiento a la propiedad privada y el cumplimiento de contratos. Estos derechos "humanos" se constituyen por lo tanto como legisladores del orden mundial o leyes fundamentales del orden.

El mismo Adam Smith es quien explica el hecho de que la "acción fragmentaria" produce el orden del mercado y todo orden del mercado es visto como efecto indirecto de la acción directa, es decir la acción fragmentaria. Todo lo anterior para desembocar en la doctrina de la mano invisible, cuyas normas son las del mercado. De tal suerte que la ética es justificada en nombre de la mano invisible, que no es otra cosa que el automatismo del mercado (Hinkelammert, 200).

En otras palabras las consecuencias de las relaciones fragmentarias, es decir las 
consecuencias indirectas de las acciones directas, como lo son las mercantiles, no son responsabilidad de quienes ejecutan la acción directa, sino son responsabilidad del automatismo del mercado, de la ontología del mercado, de la mano invisible. Hinkelammert opina que:

Solamente por este argumento la ética del mercado es transformada en ética absoluta. El argumento sostiene que el ser humano no tiene responsabilidad por los efectos indirectos de sus acciones directas porque el mecanismo del mercado contiene tendencias que transforman a estos efectos automáticamente en efectos que promueven el interés general. Por lo tanto, la responsabilidad por los efectos indirectos no corresponde al ser humano, sino a la institución-mercado vista como colectividad (Hinkelammert, 201).

Para Hinkelammert, como resultado de la ética del mercado se da la ética de la irresponsabilidad, de tal suerte que el ser humano ya no es el responsable de la consecuencia de sus acciones. Se recurre a un ejercicio filosófico por parte de los ideólogos del mercado, a la abstracción, pues se responsabiliza a una abstracción llamada mercado, de las consecuencias que sólo pueden ser producto de la acción del sujeto, de allí que el teórico alemán diga que esta ética "siendo una ética absoluta, es ética de la irresponsabilidad absoluta" (Hinkelammert, 201). Hinkelammert considera que esta ética atraviesa todo el pensamiento Burgués desde Weber hasta Hume.

Ahora bien, estas formas éticas constituidas como normas del mercado o ética del mercado, se fundan principalmente en juicios de hecho, sin embargo dichos juicios desembocan en una ética particular. De tal forma que aparece un juicio de hecho que desemboca en juicio que afirma la validez de una ética.
Es precisamente Kant, con su imperativo categórico quien hace coincidir con más lucidez las normas éticas con las del mercado (Hinkelammert, 202), si bien es cierto que el filósofo de Crítica a la Razón Pura, no tenía en mente la ética del mercado, Kant deriva las normas éticas de la posibilidad de su universalización, separándolas por completo de la pregunta por la felicidad, aquello por lo que propendía la ética en sus orígenes. Kant procede al igual que Smith con respecto a la ética: afirmándola como ética formal que se deriva en términos absolutos, de tal suerte que sus presupuestos filosóficos contienen en sí mismos la racionalidad ética del mercado. Hinkelammert recuerda que: «En la tradición de Kant se pregunta por la justificación filosófica de las normas éticas, en la tradición de Hume, en cambio, se pregunta por la necesidad de tales normas como condición de posibilidad de la racionalidad de la acción social» (Hinkelammert, 202).

Es claro entonces que el problema radical de la ética del mercado no consiste en la afirmación del mercado, pues del mismo no se puede prescindir para la acción humana, lo "nefasto" radica precisamente en que la ética del mercado se pretende erigir, tal como la kantiana, en una ética absoluta, lo que "por medio de la construcción de la autorregulación del mercado, que desemboca en la providencia del mercado y que sostiene la coincidencia entre el cumplimiento de las normas de la ética del mercado y el interés general" (Hinkelammert, 202). ¿Y en qué radica propiamente el problema dado anteriormente?, sencillamente en que se eliminan del horizonte ético y epistemológico, la relevancia de los efectos indirectos de la acción directa de los mercados, delegándosele la responsabilidad a un sujeto substitutivo y que como lo mencionamos es una abstracción: así deviene entonces la ética del mercado y la irresponsabilidad (Hinkelammert, 203). 
La propuesta teórica de Adam Smith, es la de acción medio-fin, por ello sostiene que la acción directa medio-fin se desarrolla a través del mercado y como efecto indirecto, se da la armonía. Sin embargo, estos efectos indirectos, por poco o nada intencionados que sean tienen evidentes consecuencias para la supervivencia humana, como lo evidencia el actual modelo de capitalismo globalizado, justificado desde antaño por esta lógica de acción medio-fin. Sin embargo, con el curso del tiempo, las consecuencias de las acciones indirectas se hacen cada vez más evidentes, de tal suerte que se puede tener consciencia de los efectos indirectos de la acción directa. De allí que:

Llegamos a saber, que las amenazas y las crisis globales resultan como subproducto o efectos indirectos de nuestras acciones calculadas en términos de un cálculo medio-fin fragmentario. En este caso, hace falta asumir una posición frente a éstas amenazas globales que han surgido y que podemos ubicar en sus causas. De efectos no-intencionales, se transforman ahora en efectos conocidos $y$ conscientes (Hinkelammert, 204).

Así la toma de consciencia de los efectos indirectos de las acciones directas, no sólo propenderá por una ética que busque reducir las amenazas globales, sino que ahora, desde la consciencia de los efectos indirectos y la desmitificación de los mismos, se podrá hacer frente, 0 por lo menos asumir determinada propuesta axiológica de manera crítica.

Ejemplo de lo anterior puede evidenciarse en la deuda externa del mal llamado "Tercer Mundo". Si bien la cobranza de la deuda es una acción directa que como efecto indirecto hace imposible la integración de estos países autónomamente a la economía mundial, de tal forma que no hay mucha duda en que los efectos indirectos coinciden con la intención real que motiva la acción directa del cobro de la deuda. Es una especie de "celebración de la destrucción", una clase de mística del mercado, una mística, ciertamente de la muerte (Hinkelammert, 204).

Hinkelammert menciona al respecto de esta mística y sus efectos indirectos que:

Los efectos indirectos de la acción directa pueden ser benévolos. La acción en el mercado puede promover acciones complementarias de otros, $y$ la acción común puede llevar de una manera indirecta e incluso no-intencionada a la incentivación mutua del desarrollo de las fuerzas productivas. Sobre este hecho fue construido el mito de la mano invisible del mercado y del automatismo del mercado. Este mito resulta en cuanto que se niega la existencia de los efectos destructores de la acción, eficiente en el mercado (Hinkelammert, 204).

De lo anterior se comprende que el problema del bien común se hace necesario cuando se comprenden, o entra en el horizonte de análisis, los efectos indirectos y "no-intencionados" de acción directa. Es campo por lo tanto de la ética y dado este panorama, no precisamente lo funcional de las acciones -lo que genera mayores ganancias, menor tiempo de producción, optimización de recursos-, sino la promoción y cuidado de la vida misma.

Pero, cabe entonces la pregunta, por cuál será el modelo ético que como alternativa al funcional de la lógica del mercado, y que como venimos argumentando sustenta el actual sistema globalizado transnacionalizado, -por que fundamenta sus acciones en un horizonte de legitimidad-, se proponga desde la realidad Latinoamericana. ¿O acaso estamos condenados a resistir, sin más, sin proponer, sin transformar? 
Para dar respuesta a dicha pregunta, es menester comprender que el horizonte ético desde el cual se opera en la actualidad, mediado por los "juicios de valor" no es una metodología adecuada para una propuesta americana y en correspondencia con el humanismo que nos ha sido propio en el devenir histórico que nos ha acaecido. Es por ello que Hinkelammert postula en contraposición de una ética necesaria o éticas necesarias, la ética de la "buena vida" (Hinkelammert, 205). Para el autor de La Vida o el Capital, la ética de la buena vida -como ética de la responsabilidad- es afirmada sobre juicios de hecho, lo cual presupone aquellos valores sin los cuales no es posible la convivencia humana. De tal forma que "se trata evidentemente de un juicio de hecho, que afirma la necesidad de una determinada ética. No afirma el deber de cumplir con esta ética, sino afirma, que su cumplimiento es necesario para que el ser humano pueda existir" (Hinkelammert, 205), es decir, una ética como condición de la existencia.

Para Hinkelammert la ética de la buena vida:

[...] afirma algo diferente. Sostiene que no se vive bien y como se debe vivir, sino se cumple con esta ética. Son éticas específicas de culturas, religiones o grupos sociales. Cuando una cultura excluye el alcohol, no afirma una norma necesaria, Se puede vivir tomando alcohol también. Afirma un tipo de vida buena, o una vida sagrada. Por eso la ética de la buena vida no es ética necesaria, y no puede ser derivada de algún juicio de hecho. Por esta misma razón las normas de la ética de buena vida no constituyen derechos humanos. A la luz de la ética de buena vida son opcionales. La ética necesaria, en cambio, formula los derechos humanos (Hinkelammert, 205).

Ahora bien, es importante recordar que las éticas necesarias son de vieja data. El mismo Calígula al exclamar que quisiera que su pueblo tuviese un solo cuello para cortarlo, lo expresa. Sin embargo, y he aquí lo complejo, si lo hubiera hecho, todo su ejercicio de dominio habría terminado, pues se constituiría en un suicidio, ello dado que su poder, como todo poder, descansa sobre el poder de la gente (Hinkelammert, 206). Esta misma situación se evidencia en la irracionalidad-racionalidad- del chantaje atómico, donde el verdadero mayor poder radica en la capacidad de suicidio, es decir, en quien está dispuesto a suicidarse, de tal suerte que no estar dispuesto al suicidio en la lógica del mercado no es más que una simple debilidad.

Esta idea de la autoeliminación de cualquier despotismo por el cálculo de las condiciones de su propia posibilidad como despotismo, aparece muy temprano. Pero no aparece como ética déspota, sino como ética de la banda de ladrones. La razón está en el hecho de que el déspota nunca puede actuar solo, sino necesita de la lealtad de sus colaboradores. El déspota aparece entonces como el jefe de la banda de ladrones (Hinkelammert, 206).

Ahora bien, la ética de la banda de ladrones es postulada desde tiempos del mismo Platón (Hinkelammert, 206), pues aunque no se reconozca ninguna ética, jamás se podrá prescindir de ella, porque incluso la banda de ladrones la necesita, de lo contrario no podría seguir funcionando como banda de ladrones, es necesario un mínimo de normas dentro de la banda, sino todos robando a todos, generará la destrucción misma. En otras palabras, se requiere una ética de la hipocresía. Según Hinkelammert, la misma polis se sustentaba en la ética de la banda de ladrones (Hinkelammert, 207)

En las ciencias y en especial en la filosofía termina con Adam Smith la discusión sobre la ética de la banda de ladrones. Cuando Bobbio se refiere a la posible 
diferencia entre la banda de ladrones y el Estado, reduce el problema a la discusión de la legitimidad de ellos y lo mismo hace Max Weber. Ven en el problema de la ética nada más que un problema metodológico de "juicios de valor" que se discute a nivel de juicio de gusto. Con eso la discusión sobre la ética pierde su realismo. Inclusive la reivindicación de un bien común es tratada como juicio de gusto. Sin embargo, esta negación a afrontar la discusión sería de la ética camufla un interés (Hinkelammert, 208).

\section{A manera de conclusión}

Es necesario seguir afirmando lo postulado con Platón, aquello de que la ética es condición de toda relación humana, ésta no es una decoración de la vida, sino que esta última no puede funcionar sin la primera -ética-. «Pero Platón y la discusión posterior sobre la ética de ladrones sigue otro resultado también: la sociedad, que no introduce una ética del bien común, cae necesariamente en una ética cuyo paradigma es la ética de la banda de ladrones" (Hinkelammert, 208). Es en este marco ético filosófico que se puede comprender la actual sociedad capitalista globalizada, pues ésta parte del paradigma de la ética suicida de los ladrones (Hinkelammert, 209).

Esta ética suicida se debe soportar en aquello que Hinkelammert ha denominado, el asesinato fundante, que si bien es cierto, tiene características y procesos de legitimación teológicos, en cuanto que recurren al mito del diablo o la satanización, como es el caso de Reagan para atacar el comunismo, o Bush atacando a Saddam Hussein y actualmente en Colombia con las operaciones militares "Sodoma" "Armagedón" y otras, que muestras los claros vínculos teológicos de dicho pensamiento (Hinkelammert, 2003 , 48). No será necesario profundizar aquí que dicha satanización o uso de Satanás para la legitimación de la acción misma del mal, en nombre del bien, tiene sus inicios políticos en el casamiento del cristianismo con el poder romano a partir del II siglo de nuestra era (Hinkelammert, 49).

De tal suerte que el problema de fondo con el capitalismo transnacionalizado, no es el no tener ética (como muchos economistas lo afirman, por ejemplo, Hayek), pues en efecto la tienen, se trata más bien de la disyuntiva entre sociedades que reducen la ética a la "banda de ladrones", la cual a su vez se soporta en la capacidad de suicidio y de asesinato, como lo hemos venido atestiguando, y las sociedades que se someten a estas bandas de ladrones. Al respecto opina Hinkelammert que "Efectivamente, nuestra sociedad de la estrategia de la acumulación llamada globalización", no se puede entender sino a partir del paradigma de la banda de ladrones» (Hinkelammert, 2002, 209).

Así, la perspectiva del bien común en la actualidad no surge de determinadas ideas del pasado, sino como una exigencia a las respuestas de las crisis globales, es decir como la puesta de vista en los resultados indirectos de las acciones directas.

\section{Referencias}

Freire, P. (2005). Pedagogía del Oprimido. (2º edición), México, Editorial Siglo XXI.

Guadarrama, P. (2002). Humanismo en el pensamiento latinoamericano. $2^{\mathrm{a}}$ edición. Tunja: U.P.T.C.

Hinkelammert, F. (2002). El Retorno Del Sujeto Reprimido. Bogotá: Universidad Nacional de Colombia.

-------, Franz. (2000). Crítica a la Razón Utópica. Tercera Edición. San José: DEl.

Franz. (2000). La Fe de Abraham y el Edipo Occidental. San José: DEI.

, Franz. (2003). La Violencia Sagrada del Imperio El asalto al poder mundial. Bogotá: Justicia y Vida. Franz. (2003). Solidaridad o Suicidio Colectivo. San José: Ambiente Ediciones.

Machuca, V. (2011). Cuerpos Oprimidos-Cuerpos Liberados; Humanización en la Pedagogía del Oprimido desde una Perspectiva Teológico Feminista Latinoamericana. Tesis de Bachillerato Superior (Sin Publicar). Bogotá: S.B.M.C.

Mondragón, H. (2009). Los Ciclos Económicos del Capitalismo; La crisis, ¿ccuándo y por qué? Bogotá: Ediciones Aurora.

Robinson, W. (2007). Una Teoría Económica Sobre el Capitalismo Global; Producción, clases y Estado en un mundo Transnacional. Bogotá: Ediciones desde abajo. 